\title{
SOBRE A SINTAXE LÓGICA NO TRACTATUS LOGICO-PHILOSOPHICUS
}

\author{
Rogério Saucedo Corrêa \\ Universidade Federal de Santa Maria
}

\begin{abstract}
RESUMO: Neste artigo, complemento uma intuição de lan Proops para o qual a sintaxe lógica no Tractatus Logico-Philosophicus é teoria do simbolismo. A teoria do simbolismo é a teoria da figuração. Esta é um conjunto de sete condições que uma proposição elementar deve satisfazer. Desse modo, se a teoria do simbolismo é a teoria da figuração, e se a teoria da figuração é um conjunto de condições, então a sintaxe lógica é um conjunto de condições. Estas condições mais a noção de operação formal fornecem o que é necessário para obter-se proposições complexas a partir de proposições elementares. Com isso, também esclareço alguns aspectos da discussão entre Cora Diamond e Peter Hacker sobre a sintaxe lógica no Tractatus.
\end{abstract}

PALAVRAS-CHAVE: sintaxe lógica, teoria da figuração, operação.

ABSTRACT: On this paper, I intend to complement the lan Proop's insight which Tractatus Logico-Philosophicu's logical syntax is the theory of symbolism. The theory of symbolism is the theory of representation. This is set of seven conditions that an elemental proposition need obey. According to this, if the theory of symbolism is the theory of representation and if the theory of representation is a set of conditions, then the logical syntax is a set of conditions. This conditions plus the notion of truth-operation give what is necessary to get complex propositions from the elemental propositions. From this, I clarify some points in the discussion between Cora Diamond and Peter Hacker about Tractatus's logical syntax.

KEY-WORDS: logical syntax, theory of representation, operation.

\section{INTRODUÇÃO}

Neste artigo, discuto a noção de sintaxe lógica do Tractatus Logico-Philosophicus ${ }^{1}$. Meu objetivo principal é complementar uma intuição apresentada por Ian Proops (2002) em "Logical sintax in the

\footnotetext{
${ }^{1}$ Daqui em diante abreviado por TLP e citado pelo número dos aforismos. Excetuando-se as citações do $T L P$ que uso a edição brasileira, todas as citações traduzidas são de minha responsabilidade
} 
Tractatus", para o qual a sintaxe é a teoria do simbolismo. Creio que, embora correta, esta afirmação necessita de complementação, pois a teoria do simbolismo é a teoria da figuração. Por teoria da figuração, entendo um conjunto de condições que devem ser cumpridas por uma proposição para que ela mereça o título de proposição, vale dizer, para que ela seja uma figuração. Se a sintaxe é a teoria do simbolismo, e se a teoria do simbolismo é a teoria da figuração, então a sintaxe lógica é a teoria da figuração. Uma vez que a teoria da figuração é um conjunto de condições que devem ser satisfeitas por toda e qualquer proposição que mereça o título de proposição, segue-se que a sintaxe é um conjunto de condições que as proposições devem satisfazer. Neste sentido, para que uma proposição seja uma figuração, ela deve possuir forma de afiguração, estrutura, forma lógica de afiguração, regras de tradução, relações afigurantes e ser bipolar. Se se considerar apenas as proposições elementares e desconsiderar-se outros tipos de figurações, tem-se uma sétima condição que é a exigência de uma proposição elementar ser constituída apenas e exclusivamente por nomes simples. Estas condições fornecem as linhas gerais do funcionamento tanto das proposições elementares quanto das proposições complexas (moleculares e quantificadas).

Se o que afirmei acima está correto, uma consequência é que a sintaxe lógica deve ser entendida como operando em dois níveis diferentes. No nível mais básico, ela regula o funcionamento das proposições elementares, ou seja, ela diz quando e como uma proposição merece este estatuto. No nível superior, ela permite entender como se dá a construção de proposições complexas (moleculares e quantificadas). Aqui, o procedimento é levado a cabo por meio de operações formais aplicadas às proposições elementares para obtenção de proposições complexas. Se esta distinção de níveis está correta, assim como a tese de que a sintaxe lógica é a teoria da figuração, posso esclarecer alguns aspectos obscuros da discussão entre Cora Diamond (2005) e Peter Hacker (2003) acerca da sintaxe lógica no $T L P$. No que se segue, primeiro, reconstruo a parte do artigo de Proops que contém sua intuição sobre a teoria do simbolismo como sintaxe; depois, reconstruo alguns pontos da discussão entre Diamond e Hacker 
e, por último, complemento a intuição de Proops apresentando as cláusulas da teoria da figuração como cláusulas da sintaxe lógica.

\section{A INTUIÇÃO DE PROOPS: TEORIA DO SIMBOLISMO COMO SINTAXE LÓGICA}

O objetivo geral de Proops (2002, p. 163) é resolver dois problemas que surgem no contexto dos aforismos 3.33 e 3.334 , que tratam da noção de sintaxe lógica. De acordo com 3.33, o significado dos sinais envolvidos não desempenha nenhuma função na sintaxe lógica. Isso quer dizer que a sintaxe lógica deve ser estabelecida sem recorrer aos significados dos sinais envolvidos ${ }^{2}$. Consequentemente, 3.334 afirma que as regras da sintaxe são evidentes por si mesmas. Se isso é o caso, então, em primeiro lugar, é preciso explicar o que significa dizer que as regras da sintaxe lógica são evidentes por si mesmas, uma vez que a sintaxe lógica é estabelecida enunciando-se regras puramente formais para a construção de frases bem formadas. Em segundo lugar, é preciso esclarecer que tipo de sintaxe os aforismos tratam aqui. Se se trata de uma sintaxe da linguagem natural ou de uma linguagem formal.

Além do objetivo geral, Proops tem dois objetivos particulares (PROOPS, 2002, p. 163-164). O primeiro subdivide-se em seis partes. A partir do esclarecimento da noção tractariana de sintaxe lógica, ele analisa a teoria correta do simbolismo; a inutilidade da teoria dos tipos; a importância dos fatos como portadores de sentido; o princípio do contexto; a noção de contrassenso e a solução tractariana para o paradoxo de Russell. Dadas as conclusões obtidas nesses tópicos, Proops desenvolve, como segundo objetivo particular, uma crítica à caracterização de contrassenso defendida por Diamond (1991). No que se segue, reconstruo os principais pontos da seção dedicada a teoria do simbolismo, pois é nela que consta a intuição de Proops que considero correta e profícua para esclarecer o funcionamento da sintaxe lógica tractariana.

\footnotetext{
${ }^{2}$ Respondo estas duas questões na terceira parte.
} 
Por que se faz necessário uma teoria do simbolismo? De acordo com Proops, para mostrar que uma teoria dos tipos é supérflua (PROOPS, 2002, p. 166). Aqui, o argumento geral atribuído a Wittgenstein é o seguinte: se os elementos portadores de sentido da linguagem são identificados corretamente, a possibilidade de combinações sem sentido de sinais significativos é revelada como meramente aparente. Logo, uma teoria do simbolismo mostra que qualquer teoria dos tipos é supérflua, uma vez que ela torna claro que não existem combinações contrassensuais de sinais significativos. Consequentemente, é desnecessário uma teoria dos tipos para explicar a contrassensualidade de tais combinações. Esta tese, segundo Proops, não estava desenvolvida suficientemente à época dos Notebooks, mas indica o que apareceria posteriormente. De qualquer modo, se estava correta, o que Wittgenstein queria dizer por 'regras sintáticas para funções' nada mais era do que as cláusulas da teoria do simbolismo (PROOPS, 2002, p. 167).

Em "Notes on Logic", assim como em "Moore Notes", Wittgenstein fornece algumas indicações de como seriam as cláusulas da teoria do simbolismo. As passagens citadas por Proops, respectivamente, são as seguintes:

Símbolos não são o que eles parecem ser. Em ' $a \mathrm{R} b$ ', 'R' parece um substantivo, mas não é. O que simboliza em ' $a \mathrm{R} b$ ' é que 'R' ocorre entre 'a' e ' $b$ '. (WITTGENSTEIN apud PROOPS, 2002, p. 167)

e

o símbolo de uma propriedade $\psi x$, p. ex., é que $\psi$ está à esquerda da forma de um nome. (WITTGENSTEIN apud PROOPS, 2002, p. 167)

As passagens acima são importantes porque indicam o que constará no TLP. Em especial nos aforismos 3.142 e 3.1432, será mantida a posição segundo a qual o que simboliza em uma proposição são certos fatos sobre seus sinais constituintes, ou seja, que apenas fatos expressam um 
sentido $^{3}$. Esta tese da teoria do simbolismo incipiente é posta à prova, por assim dizer, para explicar uma concepção particular de contrassenso. Neste sentido, diz o Wittgenstein de Proops (2002, p. 167):

A razão por que 'Platão Sócrates', p. ex., parece ter um sentido, enquanto 'Abracadrabra Socrates' nunca parecerá ter um sentido, é porque sabemos que 'Platão' tem um sentido, e não observamos que para que toda frase tenha um sentido, não é necessário que 'Platão' tenha sentido, mas o fato que 'Platão' está à esquerda de um nome tenha sentido. (WITTGENSTEIN apud PROOPS, 2002, p. 167)

Proops crê que a passagem acima mostra exatamente como funciona a teoria do simbolismo. Dadas 'Platão Sócrates' e 'Abracadrabra Sócrates', a contrassensualidade desta última decorre da falta de atribuição de significado ao sinal 'Abracadrabra'. Embora esta explicação funcione para 'Abracadrabra Sócrates', não parece funcionar com relação a 'Platão Sócrates', pois tanto para 'Platão' quanto para 'Sócrates' foi atribuído significado. Se é assim, porque ela parece contrassensual? 'Platão Sócrates' parece contrassensual porque se tem uma concepção equivocada acerca dos seus portadores de significado. Os portadores de significado não são os sinais, mas fatos sobre sinais (PROOPS, 2002, p. 168). Se isso está correto, então 'Platão Sócrates' é contrassensual porque não foi atribuído significado a algo. Este 'algo' ao qual não foi atribuído significado não é um sinal, mas o fato que um token de 'Platão' ocorre à esquerda do token de um nome. Esta explicação é a mesma fornecida para expressões contrassensuais com predicados, como, por exemplo, 'é vermelho é verde' (PROOPS, 2002, p. 168).

Embora Proops não identifique com maiores detalhes as cláusulas da teoria do simbolismo, um elemento pode ser indicado como sendo central na sua interpretação, trata-se da ideia de que os portadores de sentido são fatos sobre sinais. Não creio, porém, que isso seja suficiente para explicar como uma proposição tem sentido. $\mathrm{Na}$

\footnotetext{
${ }^{3}$ Proops entende que em ' $a \mathrm{R} b$ ' há um fato sobre um sinal. Creio que isto não é correto. A proposição ' $a \mathrm{R} b$ ' é um fato. Este fato não é sobre sinais, mas mostra que símbolos estão em certa relação. Neste caso em particular, uma relação espacial.
} 
verdade, penso que esta tese é incorporada no TLP como uma das sete condições para uma proposição ser uma figuração, a saber, a condição da estrutura da figuração. De qualquer modo, ela serve para Proops identificar o objetivo da teoria do simbolismo. Segundo ele, a teoria do simbolismo não diz o que um sinal significa, mas como ele significa (PROOPS, 2002, p. 175-176). Proops, no entanto, fica devendo ao leitor uma especificação mais detalhada das cláusulas da teoria do simbolismo. Farei isso mais adiante ${ }^{4}$, mas, antes, apresento alguns pontos da discussão entre Diamond e Hacker, pois, do meu ponto de vista, é um exemplo típico de discussão gerada por uma compreensão inadequada do que é e de como funciona a teoria do simbolismo no $T L P$. Por causa disso, a discussão gira ao redor do que é central acerca da sintaxe lógica sem, no entanto, tratar do que é essencial.

\section{O DIÁLOGO ENTRE DIAMOND E HACKER}

Em “Logical syntax in Wittgenstein's Tractatus", Diamond (2005) discute as críticas que Hacker (2003) faz a Conant em "Wittgenstein, Carnap and the New American Wittgensteinians". Em especial, ela critica a posição de Hacker sobre o papel da sintaxe lógica no TLP. De acordo com Diamond, Hacker lida com passagens importantes do texto tractariano de modo muito rápido e impreciso, e, além disso, faz uso questionável de analogias (2005, p. 78). Neste sentido, seu artigo é composto de três partes. Uma primeira parte dedicada ao aforismo 3.325 e a noção de governo ou controle pela sintaxe lógica. Uma segunda parte dedicada aos aforismos 3.326-3.327 e a carta de Wittgenstein para Ogden sobre a tradução de 3.326, e, uma última parte na qual ela analisa o uso que Hacker faz da analogia do jogo de xadrez para explicar o funcionamento das regras da sintaxe lógica. No que se segue, ignoro este último ponto, pois tenho interesse

\footnotetext{
${ }^{4}$ Não analisarei em detalhes cada uma das sete condições, pois apenas usarei aquelas que são importantes para esclarecer os dois problemas levantados por Proops. Para uma análise mais detalhada, o leitor poderá consultar CORRÊA (2009).
} 
em centrar minha análise em torno das questões sobre o uso de sinais de acordo com as regras de uma sintaxe lógica.

O ponto de partida é a contraposição das posições de Conant e Hacker sobre a sintaxe lógica e a geração de contrassensos. Para Hacker, contrassensos surgem quando sinais são usados de um modo que viola as regras da sintaxe lógica (DIAMOND, 2005, p. 78). O caráter contrassensual, portanto, decorre da combinação de sinais de um modo que é proibido pela sintaxe lógica. A posição de Hacker articula dois aspectos. Por um lado, se as regras permitem certas combinações de sinais, e se os sinais são combinados de acordo com as regras, o resultado são proposições legítimas. Por outro lado, se as regras proíbem certas combinações de sinais, e se eles são combinados de tal maneira que violam estas proibições, o resultado são contrassensos. Do ponto de vista de Conant, a abordagem é completamente distinta (DIAMOND, 2005, p. 79). Em primeiro lugar, porque o TLP não diz nada sobre um uso de sinais que viola a sintaxe lógica. Em segundo lugar, porque usar sinais de uma maneira que não está prevista pelos usos previamente estabelecidos pode ou não resultar em contrassensos, mas não é isso a fonte geradora deles. O que produz contrassensos, em terceiro lugar, é usar um sinal ou sinais sem atribuir-lhes um significado 5 . A diferença fundamental, portanto, entre as duas interpretações repousa na causa da contrassensualidade. Hacker afirma que é a violação das regras da sintaxe lógica e Conant que é uma falha em atribuir significado aos sinais. Como Diamond é uma das principais proponentes desta perspectiva interpretativa, ela defende Conant contra Hacker. Sua defesa, porém, tem um caráter mais negativo que positivo, pois ela busca mostrar os erros argumentativos

\footnotetext{
${ }^{5}$ Faço duas observações aqui. Em primeiro lugar, há uma semelhança entre a interpretação de Diamond/Conant e a de Proops. Para ambos a contrassensualidade está associada a falha em atribuir-se significado. Mas há uma diferença. Proops pensa que a falha está em não atribuir significado a um fato. Isso gera uma aparência de contrassensualidade que, na verdade, diz respeito a uma compreensão inadequada dos portadores de significado em uma proposição. Diamond/Conant, porém, pensam que a falha está em atribuir significado a sinais. Isso gera contrassensos que são sinais usados sem significado. Em segundo lugar, dada a caracterização que faço de uso como pensar, pode-se detectar uma ambiguidade na posição de Diamond/Conant. Se na instituição de uma proposição usar significa pensar, então ao usar um sinal não se está pensando o sentido proposicional, mas o empregando tal como um utensílio. Como Conant não distingue estes dois sentidos de usar, sua tese é ambígua.
} 
de Hacker e não apresenta uma discussão mais pormenorizada da noção tractariana de sintaxe lógica.

Como afirmei acima, a primeira parte do artigo de Diamond discute o aforismo 3.325 e a noção de controle pela sintaxe lógica. Sua estratégia é contrastar aquilo que Hacker atribui a Wittgenstein com aquilo que o próprio Wittgenstein diz. Por isso, é interessante começar por 3.325 segundo o qual:

Para evitar esses equívocos, devemos empregar uma notação que os exclua, não empregando o mesmo sinal em símbolos diferentes e não empregando superficialmente da mesma maneira sinais que designem de maneiras diferentes. Uma notação, portanto, que obedeça à gramática lógica - à sintaxe lógica. (A ideografia de Frege e Russell é uma tal notação, que não chega, todavia, a excluir todos os erros). (TLP, 3.325)

Em relação a essa passagem, Hacker afirma:

Eu concordo com Conant que no Tractatus jamais se fala em 'violações da sintaxe lógica'. Ele diz apenas que em uma notação logicamente correta, expressões serão usadas de acordo com a sintaxe lógica (TLP 3.325). Mas obviamente, não pode haver algo como usar um sinal de acordo com a sintaxe lógica se não há algo como usá-lo em contravenção a sintaxe lógica. (HACKER apud DIAMOND, 2005, p. 79)

O comentário de Hacker, como é evidente, é sobre 3.325 e possui dois pontos importantes. Por um lado, o reconhecimento de que, no TLP, não aparece nenhuma menção a ideia de violação da sintaxe lógica e, por outro lado, a afirmação de que se há um uso regrado de sinais, então deve haver um uso que viola as regras. Observe-se que esse aforismo está no escopo de 3.323 e 3.324 , que tratam do surgimento dos problemas filosóficos. O aforismo 3.323 menciona dois modos equivocados de sinais relacionaram-se com símbolos. $\mathrm{O}$ primeiro caso é quando uma palavra designa de maneiras diferentes. Por exemplo, em "Rosa é rosa" um mesmo sinal, a saber, 'rosa', significa de duas maneiras diferentes. Se isso ocorre, não se tem apenas dois sinais, mas dois símbolos diferentes, pois o sinal significa de dois modos diferentes. O segundo caso é quando duas palavras, que designam de 
maneiras diferentes, são usadas superficialmente do mesmo modo. A palavra "é", por exemplo, pode ser usada tanto como cópula quanto como identidade. É por isso que a palavra "é' não significa a mesma coisa em "A Estrela Matutina é a Estrela Vespertina" e em "Paulo é alto" e a não observância desse detalhe pode levar a confusões.

$O$ ponto central de 3.323 é destacar a presença e o funcionamento de um mecanismo que está na base do surgimento das confusões filosóficas. As confusões filosóficas surgem ou porque um mesmo sinal significa de modos diferentes, vale dizer, seja símbolos diferentes, ou porque dois símbolos diferentes estejam associados a um mesmo sinal. Como, porém, o uso de uma notação adequada pode evitar as confusões filosóficas? Excluindo-as, ou seja, colocando-as fora do discurso filosófico. A exclusão não é a única face do procedimento filosófico propugnado pelo TLP, mas um dos momentos desse procedimento. $\mathrm{O}$ outro é a identificação e, por assim dizer, denúncia do caráter contrassensual dos pseudoproblemas filosóficos, tal como vem dito em 4.003. No entanto, o ponto de discórdia entre Diamond e Hacker não é esse, mas, sim, saber se sinais podem ou não serem usados violando as regras da sintaxe lógica.

Hacker afirma que em uma notação lógica adequada os sinais são usados de acordo com as regras da notação. Dado que os sinais são usados de acordo com as regras, segue-se que faz sentido pensar que há sinais que possam ser usados violando-as. Dito de outro modo, existem usos de acordo e usos em desacordo com as regras da sintaxe lógica. Diamond, porém, não concorda com essa leitura, pois, segundo ela, não há nenhuma passagem no texto tractariano que afirme algo desse gênero ou que permita tal conclusão (DIAMOND, 2005, p. 79).

Em relação ao aforismo 3.325, a questão em jogo é de outra natureza, pois, para Diamond, ele trata do contraste entre uma linguagem de sinais aberta para certas possibilidades de confusões filosóficas e uma linguagem de sinais fechada para tais possibilidades (DIAMOND, 2005, p. 80). Essa distinção é importante para o seu argumento, pois lhe permite defender a tese que a linguagem ordinária não é governada pela sintaxe lógica. Há duas linguagens. Uma aberta para confusões e outra não. A linguagem aberta para confusões é a ordinária, enquanto a fechada é a filosófica. Se há uma linguagem 
aberta para confusões e outra não, e se esta última é a filosófica, e se a linguagem filosófica é governada pela sintaxe lógica, então a linguagem aberta para confusões, isto é, a ordinária, não é governada pela sintaxe lógica.

Creio que não existe uma diferença significativa entre o que diz Hacker e o que diz Diamond neste ponto. Se tenho uma notação adequada, ela é adequada porque possui regras para o uso correto dos sinais. Logo, ela está fechada para outros tipos de combinações. O que seria, no entanto, uma linguagem de sinais aberta para possibilidades de confusões. Não há outra resposta a não ser que esta linguagem não esteja devidamente refinada em seu aparato de regras, ou seja, não é uma notação adequada ou é aberta para certas possibilidades de confusões filosóficas. No caso de Diamond, porém, a linguagem aberta a confusões é a ordinária, uma vez que ela não é governada pela sintaxe lógica. Esta conclusão, no entanto, não é imune a críticas.

Se 3.325 está no escopo de 3.323 e 3.324 , e se 3.323 refere-se aos equívocos que ocorrem na linguagem ordinária, então parece que a leitura de Diamond está correta. Mas não é tão óbvio assim, pois há outras maneiras de ler-se estes aforismos. A primeira leitura ressalta que 3.323 menciona típicos erros de uso de sinais que ocorrem na linguagem ordinária e 3.324 afirma que as confusões que nascem, não na linguagem ordinária, mas na filosofia, nascem da mesma maneira que as da linguagem ordinária. Dito de outro modo, o mecanismo que gera as confusões em um e em outro caso é o mesmo. Se é assim, há confusões tanto na linguagem ordinária quanto na filosofia. Desse modo, 3.325 é uma complementação de 3.324. Se isto está correto, 3.325 não se refere apenas à filosofia, mas, em certo sentido, à linguagem ordinária também, pois há confusões nas duas linguagens. Se a solução para os problemas filosóficos é a adoção de uma notação lógica que os exclua, e se o mecanismo de gerar confusões é o mesmo na linguagem ordinária e na filosofia, a adoção de uma notação lógica adequada para excluir confusões não precisa ser feita apenas em relação à filosofia, mas também pode ser feita em relação à linguagem ordinária. Se o mecanismo que gera as confusões em um e no outro caso é o mesmo, e se ele tem a ver com a violação de regras da sintaxe lógica, então as duas linguagens obedecem à sintaxe lógica. Logo, 
Diamond está errada. A segunda leitura diz que os exemplos de confusões mencionados em 3.323 não são propriamente confusões filosóficas. $\mathrm{Na}$ verdade, as confusões só ocorrem na filosofia. Aqueles exemplos são uma espécie de recurso didático para o leitor ser levado a entender como funciona o mecanismo que as gera. Neste caso, só é possível concluir que a notação lógica governa a filosofia e a adoção de uma notação adequada excluiria a possibilidades de surgirem confusões tais como aquelas que 3.323 quer dar a entender. Esta interpretação, porém, não permite a conclusão de Diamond, pois ela não diz nada sobre a linguagem ordinária ser ou não governada por uma sintaxe lógica do tipo que deve ser adotado para excluir-se as confusões filosóficas. Desse modo, o argumento de Diamond padece do mesmo mal que ela atribui ao de Hacker, qual seja, não há base textual para ele. Assim, de duas uma, ou ela é ou não é governada pela sintaxe lógica. Se é, então fica-se devendo uma explicação de como isso funciona. Se não é, então também se fica devendo uma explicação plausível de porque a linguagem ordinária não é governada pela sintaxe lógica. Falta para Diamond, portanto, mostrar porque a linguagem ordinária não é governada pela sintaxe lógica. Há mais dois pontos importantes a serem considerados.

Demonstrado que a afirmação de Hacker não tem respaldo em 3.323, Diamond discute dois sentidos em que novos usos de sinais, que já possuem um uso na linguagem, podem ser proibidos pela sintaxe lógica (DIAMOND, 2005, p. 80). Neste caso, o importante é observar que usos dessa natureza não geram contrassensos. Dada uma linguagem $L$, suponha que alguém fala algo novo usando um sinal já existente e regrado por $L$. Neste caso, o novo uso não é regrado por $L$. Se esse uso não é regrado por $L$, então ele viola as regras de $L$. Isso não significa, porém, que este novo uso gere contrassensos. Segundo Diamond, usos desse tipo podem contradizer $L$ de duas maneiras. No primeiro caso, alguém introduz confusamente um novo modo de falar e afirma que os sinais foram usados violando a sintaxe lógica, caso eles tenham mais de um uso. Esse é o primeiro uso que contradiz $L$. No segundo caso, alguém diz que um sinal é usado violando a sintaxe lógica e violar a sintaxe lógica significa usar o sinal em uma notação na qual há uma regra explícita que exclui este uso. Nenhum desses casos, afirma 
Diamond, gera contrassensos (DIAMOND, 2005, p. 80-81). Como já disse acima, contrassensos são gerados quando um significado não é atribuído a um sinal, ou seja, ele é gerado por causa de uma falha.

No segundo momento do artigo de Diamond, ela discute os aforismos 3.326-3.327 e a carta de Wittgenstein para Ogden sobre 3.326 (DIAMOND, 2005, p. 81). A questão central é a crítica de Hacker a Conant para quem a sintaxe lógica não proíbe combinações de sinais, pois ela trata de símbolos. Hacker, como já se sabe, sustenta que a sintaxe lógica regula certas combinações de sinais e proíbe outras. Conant afirma que não, pois ela não proíbe combinações de sinais, uma vez que ela diz respeito a símbolos. Esta tese não apenas é falsa, pensa Hacker, mas confusa, pois admite que existam símbolos contrassensuais e nega que existam sinais contrassensuais, ignorando que símbolos dependem de sinais. Se um símbolo é um sinal usado de acordo com as regras para seu uso correto, então devem existir sinais contrassensuais, pois o símbolo depende, de certo modo, do sinal. Hacker, portanto, recorre a noção de regras para um uso correto de sinais. As passagens relevantes para a afirmação de Hacker sobre sinais e símbolos são 3.326-3.327 e 3.32-3.321:

O sinal é aquilo que é sensivelmente perceptível no símbolo.

Dois símbolos diferentes podem ter, portanto, o sinal (escrito ou sonoro, etc.) em comum - designam, nesse caso, de maneiras diferentes.

Para conhecer o símbolo no sinal, deve-se atentar para o uso significativo.

É só com seu emprego lógico-sintático que o sinal determina uma forma lógica.

Segundo os aforismos acima, é permitido que múltiplos símbolos tenham sinais em comum. Desse modo, um sinal $x$ qualquer tomado junto com um modo de emprego constitui um símbolo e o mesmo sinal $x$ tomado com outro modo de emprego constitui um símbolo diferente. Neste ponto, Diamond acusa Hacker de concluir indevidamente que um símbolo é um sinal usado de acordo com as regras para seu uso correto, uma vez que ele deseja que outros modos de uso sejam incorretos (DIAMOND, 2005, p. 83). Isso é impreciso porque o texto do $T L P$ não faz nenhuma referência a noção de correção de uso. Embora o texto não faça menção a noção de uso correto, para 
Diamond, não há problema nenhum em falar-se de correção para explicar as teses sobre sinais e símbolos, desde de que se use uma noção fraca de correção. É essa noção fraca que é mencionada na carta a Ogden. A noção fraca de correção é sintática. O exemplo proposto por Diamond é 'Rosa é rosa'6, onde tem-se duas ocorrências de 'rosa' (DIAMOND, 2005, p. 82). Isso significa que se tem dois símbolos diferentes, ou seja, a primeira e a segunda ocorrência do mesmo sinal significam de modos diferentes. Portanto, são símbolos diferentes. Embora o sinal 'rosa' ocorra em dois lugares diferentes na frase, ele não viola nenhuma regra sintática. Logo, do ponto de vista sintático, ele tem um uso correto. Para Diamond, a tese de Hacker segundo a qual um símbolo é um sinal usado de acordo com as regras para seu uso correto não está errada, se por uso correto entender-se o sentido fraco de uso correto. Mas se é assim, disso não se segue que quaisquer usos sejam excluídos pelo que é estabelecido por um uso correto. Logo, isso não fornece suporte para o argumento de Hacker contra Conant. Portanto, finaliza Diamond, Hacker não fornece nenhuma evidência de que a discussão sobre sinais e símbolos é conectada com a noção de uso correto tal que outros usos são passíveis de exclusão.

\section{SINTAXE COMO TEORIA DA FIGURAÇÃO}

Um aspecto dúbio da discussão descrita acima é sobre a própria noção de sintaxe lógica do TLP. Hacker diz que os sinais são governados pela sintaxe lógica e Diamond diz que a linguagem natural não é governada pela sintaxe lógica e dá a entender que a filosofia é regrada pela sintaxe, mas nenhum dos dois afirma o que entende por sintaxe lógica. Se Diamond diz que a linguagem ordinária não é regrada pela sintaxe e a filosofia sim, então a diferença entre Diamond e Hacker é que, para ela, a filosofia obedece a sintaxe e, para Hacker, tanto a linguagem ordinária quanto a filosofia obedecem a sintaxe lógica. Mas não é claro como se deve entender esta noção. Se ela deve

\footnotetext{
${ }^{6} \mathrm{O}$ exemplo original de Diamond é "Green is green” que é a tradução inglesa de 'Grün ist grün'. Portanto, em nítida referência a 3.323 .
} 
ser entendida como "uma teoria formal das formas linguísticas da linguagem - a expressão sistemática das regras que a governam junto com o desenvolvimento das consequências que se seguem dessas regras" (CARNAP, 1959, p. 01), se ela é a gramática de um cálculo de predicados, ou ainda se é um dos componentes de uma gramática modelo. Este é um ponto fundamental a ser esclarecido. $\mathrm{Na}$ discussão entre Diamond e Hacker, parece que um dos sentidos de sintaxe lógica é o de gramática de um cálculo. $\mathrm{O}$ outro que aparece claramente é o linguístico. Começo minha análise por este último.

Para a semântica formal ${ }^{7}$, a análise de determinada língua é realizada a partir da construção de uma gramática modelo. Chamarei esta gramática de $G^{9}$. Suponha que tenho um fragmento da língua portuguesa para ser analisado e que ele consiste das frases "João olha para Maria” e "Maria transpira". Para tanto, G' deve conter uma sintaxe e uma semântica. A sintaxe é formada pelo léxico e as regras sintáticas, ou seja:

. Sintaxe de G’:

1. Léxico

a) Os membros da categoria $N$ (nome) são: João, Maria, ...

b) Os membros da categoria $V_{i}$ (verbos intransitivos) são: dorme, transpira, ...

c) Os membros da categoria $V_{t}$ (verbos transitivos) são: ama, olha para, ...

2. Regras sintáticas

As frases bem formadas são cadeias de elementos com a seguinte forma:

d) $N V_{i}$

e) $N V_{t} N$

. Semântica de G':

3. Regras semânticas

Para toda possível circunstância de emissão $t$,

f) os membros da categoria $N$ denotam indivíduos: João denota em $t$ o estudante de filosofia do terceiro semestre do curso de filosofia da UFSM em 2014;

\footnotetext{
${ }^{7}$ Investigação formal das relações de significado (OLIVEIRA, 2001, p. 28).

${ }^{8}$ Neste ponto, uso o modelo de Chierchia (2003, p. 84-85) com algumas adaptações.
} 
g) Os membros da categoria $V_{i}$ denotam classes de indivíduos: dorme denota em $t$ o conjunto $\{x: x$ dorme em $t\}$, transpira denota em $t$ o conjunto $\{x: x$ transpira em $t$;

h) os membros da categoria $V_{t}$ denotam relações entre indivíduos: ama denota em $t$ a relação $\{\langle x, y\rangle: x$ ama $y \mathrm{em} t\}$, olha para denota em $t$ a relação $\{\langle x, y\rangle$ : $x$ olha para $y$ em $t$, etc.;

i) Uma frase com a forma $N V_{i}$ é verdadeira em $t$ sse $u \in A$, onde $u$ é o indivíduo denotado por $N$ em $t$ e $A$ é a classe denotada por $V_{i}$ em $t$,

j) Uma frase com a forma $N V_{t} N$ é verdadeira em $t$ sse $R(u, u)$, onde $u$ é o indivíduo denotado pelo primeiro $N$ em $t$, u' é o indivíduo denotado pelo segundo $N$ em $t$ e $R$ é a relação denotada por $V_{t}$ em $t$.

De posse de G', posso mostrar que qualquer frase construída de acordo com as suas regras sintáticas e semânticas é uma frase bem formada e com sentido. Esta afirmação, porém, é ambígua, pois posso construir frases bem formadas desde que seus componentes estejam contemplados no léxico. Se eu construir uma frase como "Todo homem voa", por exemplo, isso não significa que tenho uma frase mal formada. Significa simplesmente que não tenho uma gramática modelo completa capaz de fornecer os elementos necessários para analisá-la. Neste caso, a única coisa que devo fazer é complementar minha gramática modelo. Faço isso especificando as entradas lexicais, as regras sintáticas e semânticas dos elementos que formam a frase "Todo homem voa" e que não estão contemplados em G’. Não significa, portanto, que esta frase é mal formada. Há um sentido, porém em que posso obter uma frase mal formada mesmo que me restringindo a G'. Se em vez de escrever "João olha para Maria" eu escrever "Para olha João Maria”, então tenho uma frase mal formada a partir de G'. Este é, diga-se de passagem, o sentido fraco ou linguístico descrito por Diamond. Certamente que a noção de sintaxe lógica do TLP não é esta, pois não há nenhuma afirmação sobre isso e nada que permita inferir isso do texto tractariano. Resta, portanto, o outro sentido de sintaxe lógica.

O procedimento para a construção de um cálculo de predicados de primeira ordem, por exemplo, tem semelhanças com o que foi descrito acima. Assim como para G', um cálculo de predicados terá uma sintaxe e uma semântica. Dada a sintaxe, posso dizer quando tenho uma fórmula bem formada, e, dada a semântica, posso 
estabelecer as condições de verdade de uma fórmula do cálculo de predicados. Consequentemente, posso dizer quando e como tenho uma fórmula bem formada com sentido. Neste sentido, se a linguagem geral do cálculo de predicados de primeira ordem for ${ }^{9}$ :

a) Um conjunto enumerável de constantes individuais;

b) para cada número natural $\mathrm{n} \geq 0$, um conjunto enumerável de constantes de predicados n-árias;

c) um conjunto enumerável de variáveis individuais;

d) operadores;

e) quantificadores;

f) sinais de pontuação

E dadas as definições de linguagem de primeira ordem $\left(L_{1}\right)$ e de termos de uma linguagem de primeira ordem $\left(T_{1}\right)$, isto é:

$\left(L_{1}\right)$ uma linguagem de primeira ordem é qualquer subconjunto da linguagem geral do Cálculo de predicados de primeira ordem que inclua todos os símbolos lógicos e, pelo menos, uma constante de predicados;

$\left(T_{1}\right)$ Os termos de uma linguagem de primeira ordem são suas variáveis e constantes individuais.

Segue-se que posso fornecer uma definição das fórmulas de uma linguagem de primeira ordem, ou seja:

1) Se $P$ é um símbolo de predicado $n$-ário, para um número natural $n \geq 0$, e $t_{1}, \ldots, t_{n}$ são termos, então $P t_{1} \ldots P t_{n}$ é uma fórmula (atômica);

2) Se $\alpha$ e $\beta$ são fórmulas, então $\neg \alpha,(\alpha \vee \beta),(\alpha \wedge \beta),(\alpha \rightarrow \beta)$ e $(\alpha \leftrightarrow \beta)$ são fórmulas (moleculares);

3) Se $x$ é uma variável e $\alpha$ é uma fórmula na qual $x$ ocorre, então $\forall x \alpha$ e $\exists x \alpha$ são fórmulas (gerais);

4) Nada mais é uma fórmula.

Aqui, valem as mesmas observações que fiz sobre G'. Construo uma linguagem artificial e, de posse dela, analiso frases e argumentos da

\footnotetext{
${ }^{9}$ Retiro este modelo de Mortari (2001, p. 98-101), mas o leitor pode encontrar outros modelos como em Mendelson (1987).
} 
língua ordinária. Logo, posso dizer se uma fórmula é ou não bem formada e se ela tem ou não sentido de acordo com as regras estipuladas. Mas não é este modelo de sintaxe que está pressuposto no $T L P$, pois, assim como no caso anterior, não há nenhuma afirmação e nenhuma evidência no TLP que permita inferir isso. Logo, se Diamond e Hacker pressupõem esta noção de sintaxe, eles estão errados. Diferentemente disso, penso que a sintaxe tractariana, como bem intuiu Proops, é a teoria do simbolismo cujos pressupostos filosóficos obrigam Wittgenstein a não se comprometer com um procedimento semelhante aos dois descritos acima. Por quê? Basicamente, porque as regras da sintaxe não podem ser descritas, uma vez que apenas fatos podem ser descritos (TLP, 2.1).

No TLP, a teoria do simbolismo é a teoria da figuração e esta é a sintaxe lógica. Portanto, o sentido em que esta deve ser entendida é muito diferente do sentido com a qual ela é usualmente entendida nos manuais de lógica ou semântica formal. As cláusulas da teoria da figuração são a forma de afiguração, a estrutura da figuração, forma lógica de afiguração, as regras de tradução, as relações afigurantes e a bipolaridade. Estas seis condições são válidas para a noção geral de figuração ${ }^{10}$. Como o TLP aplica a noção geral de figuração à linguagem a fim de concluir que proposições são figurações lógicas de fatos, seguese uma sétima condição para este caso que é a exigência de uma proposição ser composta apenas e exclusivamente de nomes simples ${ }^{11}$. Proposições devem ser compostas apenas de nomes simples por causa do princípio da determinabilidade do sentido, o qual é a garantia do término da análise proposicional (TLP, 3.23). A exigência de nomes simples permite, em partes, explicar porque proposições complexas como uma conjunção, por exemplo, não apresentam um ganho material ao serem instituídas a partir de proposições elementares. A

\footnotetext{
${ }^{10}$ No grupo dois de aforismos Wittgenstein desenvolve uma concepção geral de figuração que, posteriormente, no grupo três é estendida ao pensamento e à proposição. Esse movimento argumentativo fica evidenciado por meio dos aforismos 2.1, 3 e 4 .

${ }^{11}$ Como já afirmei anteriormente, não analisarei cada uma dessas cláusulas em detalhes, pois me restrinjo a usar aquelas que são diretamente mais pertinentes para as questões que Proops levanta. Para uma discussão mais pormenorizada, o leitor pode consultar CORRÊA (2009).
} 
outra parte da explicação fica por conta da noção de operação formal que é expressa pela presença do operador de conjunção.

Restringindo-se às proposições elementares as noções de forma de afiguração e forma lógica de afiguração são fundamentais para entender-se que as possibilidades combinatórias dos nomes simples são isomórficas às possibilidades combinatórias dos objetos simples. Estas condições aparecem em 2.18-2.2:

O que toda figuração, qualquer que seja sua forma deve ter em comum com a realidade para poder de algum modo - correta ou falsamente - afigurá-la e a forma lógica, isto é, a forma da realidade.

Se a forma de afiguração é a forma lógica, a figuração chamase figuração lógica.

Toda figuração é também uma figuração lógica. (No entanto, nem toda figuração é p. ex. uma figuração espacial.)

A figuração lógica pode afigurar o mundo.

A figuração tem em comum com o afigurado a forma lógica de afiguração.

Os aforismos acima contrastam a forma de afiguração e a forma lógica de afiguração. Observe-se que a forma de afiguração é concebida como uma espécie de região menor que a forma lógica de afiguração, pois, independentemente da forma de afiguração, toda e qualquer figuração deve possuir uma forma lógica de afiguração. Enquanto a forma de afiguração é a forma de uma porção da realidade afigurada, a forma lógica de afiguração é a forma do espaço lógico. Este é a totalidade das possibilidades combinatórias dos objetos simples. É por isso que quando uma figuração é instituída, ela possui concomitantemente uma forma de afiguração e uma forma lógica de afiguração. Como as possibilidades combinatórias dos nomes simples é idêntica às possibilidades combinatórias dos objetos simples, garante-se que não ocorra incompatibilidade entre o nível da linguagem e o nível da realidade. Por que isso é importante? Porque me permite mostrar um ponto obscuro na discussão entre Diamond e Hacker. Para tanto, necessito introduzir um último elemento. Trata-se da noção de método de projeção, que também me permite esclarecer o sentido da expressão 'uso' neste contexto. Assim, de acordo com 3.11: 
Utilizamos o sinal sensível e perceptível (sinal escrito ou sonoro, etc.) da proposição como projeção da situação possível.

O método de projeção é pensar o sentido da proposição.

'Usar', aqui, não significa a mesma coisa que dar ordens, fazer pedidos ou exclamações, mas projetar uma situação possível no sinal proposicional. Projetar, por sua vez, é pensar o sentido da proposição. Logo, usar nada mais é que pensar. Há, no entanto, outras passagens em que 'usar' aparece com outro sentido. Por exemplo, ao caracterizar o sinal de identidade em 4.241-4.242 como um recurso de abreviação a expressão 'uso' não significa pensar o sentido proposicional, mas algo como empregar um utensílio para determinado fim. Neste caso, portanto, ela tem a conotação que os resolutos aplicam indiscriminadamente ao TLP. Se isso está correto, usar uma proposição é apenas e simplesmente projetar uma situação possível em um sinal proposicional, e, projetar uma situação possível é pensar o sentido proposicional. Deve-se observar, no entanto, que se trata da instituição de uma proposição e não do uso que se pode fazer de sinais em um procedimento de demonstração tal como é descrito em 6.241, por exemplo. Além disso, trata-se da instituição de proposições elementares, isto é, proposições cujos constituintes são apenas e exclusivamente nomes simples. Para visualizar o que eu disse até aqui e o que virá a seguir, o leitor pode imaginar uma proposição complexa do tipo $(\mathrm{P} \rightarrow$ Q) $\vee(P \& \sim Q)$, como se fosse uma árvore de cabeça para baixo. Cada ramo da árvore termina numa folha que são as proposições elementares. Neste caso, 'P' e 'Q'. A teoria da figuração, portanto, visa a explicar como as proposições elementares são instituídas. Uma proposição é uma figuração se e somente se ela possui as sete condições; caso contrário ou ela é um sem sentido ou um contrassenso. Isso significa dizer que não são proposições. Explicado isso, resta saber como os ramos da árvore são construídos. Isso fica por conta da noção de operação formal. 
Operações são procedimentos recursivos ${ }^{12}$ para construção de proposições a partir de uma proposição (TLP, 5.23). Nos casos em que o resultado da aplicação de uma operação for uma função de verdade, tem-se uma operação de verdade. Aqui, é útil citar um exemplo para cada caso e depois explicá-los.
1) $\sim \mathrm{p}={ }_{\mathrm{Df}} N \mathrm{p}$
2) $(\mathrm{P} \rightarrow \mathrm{Q}) \vee(\mathrm{P} \& \sim \mathrm{Q})$

Em (1) há um procedimento de definição de acordo com o qual as duas expressões que ladeiam o sinal de identidade são mutuamente substituíveis. No entanto, da determinação dos valores de verdade de ' p' e 'Np' não se segue que os valores de verdade de (1) esteja determinado. Por isso, embora a identidade seja uma operação, ela não é uma operação de verdade. Em (2), porém, dados os valores de verdade de 'P' e 'Q', segue-se que os valores de verdade de '(P $\rightarrow \mathrm{Q}) \vee(\mathrm{P} \&$ $\mathrm{Q})$ ' estão determinados. Isso ocorre porque ' $(\mathrm{P} \rightarrow \mathrm{Q}) \vee(\mathrm{P} \& \sim \mathrm{Q})$ ' é uma função de verdade de 'P' e 'Q'. Dado isso, e uma vez que '( $P \rightarrow Q)$ $\vee(\mathrm{P} \& \sim \mathrm{Q})$ ' é obtida mediante a aplicação reiterada de operações às proposições 'P' e 'Q', então se tem uma operação de verdade funcionando na obtenção de (2) e não apenas uma operação. A operação é indicada pelos sinais dos conectivos lógicos. Como (2) possui quatro sinais para conetivos lógicos, foram aplicadas quatro operações às proposições 'P' e 'Q'. Estas operações, na verdade, não são aplicadas às proposições elementares, mas às suas estruturas (TLP, 5.2). É por isso que operações são procedimentos formais, ou seja, procedimentos cujos resultados não acrescentam nenhum acréscimo material às proposições obtidas. Esta é apenas uma outra maneira de explicar a máxima tractariana segundo a qual as constantes lógicas não significam $(T L P, 4.0312 \text { e } 5.4)^{13}$. Elas não significam simplesmente porque são operações com as quais obtenho proposições e, como tais,

\footnotetext{
${ }^{12}$ Aplicados reiteradamente como em p, $\sim$ p e $\sim$ p. Para uma análise detalhada dessas noções, ver CUTER (2005).

${ }^{13}$ Neste contexto, significar quer dizer fazer as vezes dos objetos na proposição.
} 
são formais. Para finalizar, quero fazer uma observação sobre o caráter evidente das regras sintáticas.

Novamente é útil usar um exemplo para depois explicar o ponto em questão. Para tanto, suponha que tenho a proposição complexa ' $\mathrm{P} \&$ Q'. Em primeiro lugar, 'P \& Q' é uma proposição molecular, obtida por meio de uma operação de verdade a partir das proposições elementares 'P' e 'Q'. Se o TLP não possui uma concepção de sintaxe tal como a do cálculo de predicados que descrevi acima, então como ela pode ser obtida? Ela é obtida, em segundo lugar, mediante a aplicação de uma operação de verdade à 'P' e 'Q', indicada pela presença do sinal de conjunção. Posso explicitar esta operação formulando-a em termos de uma regra (CORRÊA, 2008, p. 149). Isso, no entanto, não é essencial, pois se sei como funciona a lógica da linguagem, então sei que proposições elementares são instituídas de acordo com sete condições e proposições complexas são obtidas por meio de operações formais e não preciso nada mais, a não ser a própria linguagem para compreender isso. É nesse sentido, portanto, que as regras da sintaxe lógica são evidentes e, consequentemente, não necessitam ser descritas.

\section{ALGUMAS CONSIDERAÇÕES A TÍTULO DE CONCLUSÃO}

A título de conclusão alinhavo tudo o que foi discutido até aqui. Minha motivação inicial era complementar uma intuição de Proops, segundo o qual a sintaxe lógica no TLPé a teoria do simbolismo. Neste sentido, mostrei que a teoria do simbolismo é a teoria da figuração que, por sua vez, nada mais é que um conjunto de condições apresentadas ao longo do TLP e que devem ser cumpridas por uma proposição para ela merecer este título. Se isso ocorre, então ' $a \mathrm{R} b$ ', por exemplo, tem sentido porque mostra que um símbolo está ao lado do outro, ou seja, ela é um fato, mas não um fato que descreve um sinal, como pensa Proops.

Se é certo que a teoria da figuração é a sintaxe lógica, então fica claro que ela não é nem uma sintaxe ao estilo da semântica formal nem uma sintaxe ao estilo do cálculo de predicados de primeira ordem. $\mathrm{Na}$ discussão entre Diamond e Hacker, é notório que eles não concebem a 
sintaxe tractariana ao estilo da semântica formal, mas não é notório que eles não a concebem como a sintaxe do cálculo de predicados. É por isso, do meu ponto de vista, que muitos aspectos da discussão entre eles são obscuros.

Por último, mostrei que as proposições complexas são obtidas a partir das elementares por meio de um procedimento denominado de operação de verdade. Como este procedimento possui uma característica fundamental que é o seu caráter formal, e como a presença de sinais para conectivos lógicos são indicativos de operações formais e não de nomes simples adicionais, então explica-se assim porque as proposições elementares não possuem acréscimo de conteúdo material em relação as proposições elementares a partir das quais elas são construídas. As operações podem ser explicitadas formulando a regra com a qual obtenho as proposições complexas. Isso, no entanto, não é essencial e não se confunde com descrever as regras da sintaxe lógica no nível complexo. Como isso não é essencial e se sei como funciona a lógica da linguagem, então entendo que as regras sintáticas são evidentes, pois a linguagem fornece-me tudo aquilo que é necessário.

\section{REFERÊNCIAS}

CARNAP, Rudolf. The logical syntax of language. New Jersey: Littlefield, Adams \& Co. 1959.

CHIERCHIA, Gennaro. Semântica. Campinas: Editora UNICAMP. 2003.

CUTER, João Vergílio Gallerani. Operations and truth-operations in the Tractatus. Philosophical Investigations, v. 28, n. 01, 2005. pp. 63-75. CORRÊA, Rogério Saucedo. A negação como uma operação formal. $O$ que nos faz pensar, n. 23, 2008. pp.143-151.

- Pensamento e figuração no Tractatus Logico-Philosophicus. Aurora, v. 21, n. 29, 2009. pp. 425-435.

DIAMOND, Cora. Logical syntax in Wittgenstein's Tractatus. The Philosophical Quartely, v. 55, n. 218, 2005. pp. 78-89. 
What nonsense might be. In.: . The Realistic Spirit: Wittgenstein, Philosophy and the Mind. Cambridge: MIT Press.1991. HACKER, Peter. Wittgenstein, Carnap and the new american wittgeinsteinians. The Philosophical Quartely, v. 53, n. 210, 2003. pp. 01-23.

MENDELSON, Elliott. Introduction to mathematical logic. Monterey: Wadsworth \& Brooks. 1987.

MORTARI, Cezar. Introdução à lógica. São Paulo: Editora UNESP. 2001.

OLIVEIRA, Roberta Pires de. Semântica Formal. Campinas: Mercado das Letras. 2001.

PROOPS, Ian. Logical syntax in the Tractatus. In.: GARSKIN, Richard. Grammar in early twentieth-century philosophy. London: Routledge. 2002. pp. 163-181.

WITTGENSTEIN, L. Tractatus logico-philosophicus. Tradução de Luiz Henrique Lopes dos Santos. São Paulo: EDUSP, 1993. 